\title{
The Response Surface Methodology for Optimizing the Process Parameters of Selective Laser Melting
}

\author{
Mathieu Terner*, ${ }^{*}$, Thibaud Ricordel**, Jae-Hung Cho***, and Jeong-Seok Lee* \\ *Department of Materials Science and Engineering, Changwon National University, Changwon, 51140, Korea \\ **Ecole des Mines d'Albi, Institut Mines-Telecom, Albi, 81000, France \\ ***Winforsys Co., Ltd., Yongin, 16827, Korea
}

†Corresponding author : mathieu@changwon.ac.kr

(Received December 3, 2018 ; Revised December 18, 2018 ; Accepted January 2, 2019)

\begin{abstract}
Additive Manufacturing and Selective Laser Melting in particular have emerged for a few years as an outstanding alternative to conventional manufacturing for low production of highly complex and/or customized products and parts. The potential for production of very high density parts with excellent mechanical properties however necessitates thorough optimization of the process and its numerous parameters. A method for optimization adapted from the Response Surface Methodology seems the most appropriate. It consists in varying the process parameters according to an experimental design and record a response characteristic of the quality of the product. To illustrate this approach, a CoCr-Mo alloy has been produced by Selective Laser Melting with different combination of scanning speed and laser power, and the porosity and hardness of the as-built materials were measured and compared. This allowed determining a suitable processing window for such alloy. The possibility to produce high density parts (porosity $\leq 0.1 \%$ ) is demonstrated and highlights the value of the optimization method.
\end{abstract}

Key Words : Additive manufacturing, Selective laser melting, Process optimization, Response surface methodology, Porosity, Microstructure

\section{Introduction}

Additive Manufacturing (AM) has been widely promoted over the past two decades for the fabrication of complex parts with high value. Although issues related to reliability, cost effectiveness and reproducibility are still matter of concerns, the outstanding potential of AM and its many different technologies is undeniable ${ }^{1-10)}$. For manufacturing metallic products in particular, AM offers a freedom in design complexity and customization unmatched by conventional manufacturing processes.

Powder bed fusion (PBF) and directed energy deposition (DED) as defined by ASTM International decidedly emerged as the preferred approaches for many applications ${ }^{11-15)}$. PBF processes such as Selective Laser Melting/Sintering (SLM/SLS) and Electron Beam Melting (EBM) offer outstanding opportunities in terms of complex design versatility and materials properties. PBF technologies involve the precise deposition of a pre-alloyed powder layer which is selectively melted or sintered according to the $\mathrm{CAD}$ profile by the power source in an inert environment. The building platform is subsequently lowered by one layer thickness and the process is repeated until the entire part(s) has/have been built. The successful production of high quality parts depends on the optimization of the several process parameters. PBF processes and SLM in particular have been extensively studied in recent years all over the world especially for applications in the fields of automobile, aerospace, tooling and medical. A wide range of materials with outstanding properties have been produced such as superalloys ${ }^{16-23)}$, steels $^{24,25)}, \mathrm{Al}$ alloys ${ }^{26-30)}$, Ti alloys ${ }^{31-35)}$, CoCr-Mo alloys ${ }^{36-39)}$, etc. For the most part, optimization of the process consists in determining the appropriate set of parameters in order to produce parts with the highest possible density, which has often been measured well over $99 \%{ }^{16-19,21,24,26,28,32,33)}$.

Journal of Welding and Joining, Vol.37 No.1(2019) pp27-39

https://doi.org/10.5781/JWJ.2019.37.1.4 
For the SLM process itself, many parameters have to be taken into consideration. For a given equipment, the parameters with the most influence are typically: the layer thickness, the hatch spacing, the scanning speed, the laser power, the scanning strategy, and the protective gas environment inside the building chamber. Although the optimization campaign is well known to researchers and industrials familiar with AM processes, there are to our knowledge no published articles focusing solely on this approach to serve as a guide for SLM, and more generally AM, process optimization. This is the scope of the present paper to clearly define the process parameters and their influence, and more importantly to fully describe the optimization campaign for SLM processing. In the present report, we focused on the optimization method for SLM processing. This typically follows the response surface methodology (RSM) which consists in varying process parameters and recording a response ${ }^{40-42)}$. This versatile method is described in details and opportunely illustrated for a CoCr-Mo alloy. It allowed to define an optimum processing window for the reliable production of dense parts.

\section{Materials and Method}

\subsection{SLM equipment}

The SLM apparatus used for the present study was a METALSYS 150 produced by the Korean company Winforsys Information Technology Co., Ltd. (http://www. winforsys.com/). This machine is equipped with a 200 $\mathrm{W}$ Yb-fiber laser with a wavelength of $1.075 \mu \mathrm{m}$. The beam spot is approximately $70 \sim 150 \mu \mathrm{m}$, and the travel speed reaches $7 \mathrm{~m} \cdot \mathrm{s}^{-1}$. The building volume for this small equipment is $150 \times 150 \times 150 \mathrm{~mm}^{3}$ under Nitrogen or Argon atmosphere and the temperature within the chamber can be regulated up to $80{ }^{\circ} \mathrm{C}$.

Metal powder layers are formed by a raking mechanism. The powder is fed from the hoppers and precisely spread onto the building platform by a silicon blade. Typically, the layer thickness is in the range 20 to 100 $\mu \mathrm{m}$ with a high precision of $\pm 3 \mu \mathrm{m}$. The laser beam scans over the powder layer and selectively melts the powder into solid and dense metal according to the CAD model. The building platform is then lowered by one layer thickness, a new layer of powder is deposited and the melting process is repeated to build the parts layer-by-layer. The whole process takes place under inert atmosphere, typically an Ar flow, to avoid oxidation and impurities pick-up. When all layers have been processed, the parts rest inside the chamber and can be removed from the powder bed. The parts can subsequently be washed and separated from the building platform which is reused after slight machining. The unprocessed powder can easily be disintegrated, sieved, and inserted again in the SLM machine to be reused in the next build thanks to very low impurities pick-up, therefore material waste is very limited.

\subsection{SLM process optimization}

The systematic approach for optimizing the SLM process consists in determining the most suitable set(s) of parameters for a given material. SLM can be assimilated to a micro-welding process, in which parts are consolidated by successfully joining powder tracks melted by the laser both in the layer plane and the building direction normal to the layer plane. Therefore, the success of the process essentially resides in the appropriate melting and consolidation of the welding tracks. For a given equipment, the parameters with the most influence are typically: the layer thickness $t$ corresponding to each layer, the hatch spacing $h$ corresponding to the distance between two adjacent scanning tracks within a layer, the scanning speed $v$ corresponding to the scanning speed of the laser tracks, the laser power $P$, the scanning strategy corresponding to the overall path followed by the laser during selective melting of the powder, and the protective gas environment inside the building chamber. The amount of energy for melting at a given point is conventionally described by the energy density $E_{d}\left(\mathrm{~J} \cdot \mathrm{mm}^{-3}\right)$ :

$$
E_{d}=\frac{P}{v \times t \times h} \times 10^{6}
$$

Where $P$ is the laser power in $\mathrm{W}, v$ is the laser scanning speed in mm.s ${ }^{-1}, t$ is the layer thickness in $\mu \mathrm{m}$ and $h$ is the hatch spacing in $\mu \mathrm{m}$. From Eq. (1), a small variation of the principal process parameters values significantly influence the energy density. Besides, same values of energy density are possible with very different parameters values, for example the couple $P / v$.

For this reason, an approach based on the response surface methodology (RSM) is usually preferred to investigate the effect of the different process parameters and determining the appropriate set of parameters for a given alloy ${ }^{40-42)}$. This empirical method is commonly used for processes to optimize a response influenced by several independent variables, here the process parameters aforementioned. Based on the RSM, the optimization campaign consists in defining matrices and building samples simultaneously using different sets of parameters. The layer thickness $t$ should be determined according to several factors. The layer thickness evidently affects the parts building time. It is therefore convenient to max- 
imize the layer thickness, sometimes at the expense of definition, in order to maximize production rates usually much lower compared to conventional manufacturing. The layer thickness is however dictated by the melt pool geometry, depth or penetration in particular. The pre-alloyed powders size is also an important limiting factor, principally on the lower bond. The successive deposition of powder layers and their consolidation suggest remelting of underlying material. As it will be discussed later in section 3.3, this is usually accompanied by epitaxial solidification and evidenced by columnar microstructures with elongated grains in the building direction intercepting several layers. The melt pool geometry depends on the laser power $P$, the scanning speed $v$ and the scanning strategy, as well as the alloy's thermal properties. Obviously, the layer thickness can't be varied from one sample to another during a single process. The hatch spacing $h$ should similarly be determined according to the melt pool geometry. Sufficient overlapping of adjacent melt tracks, preferably between 20 and $30 \%$, is necessary to insure appropriate consolidation. Valuable information about the melt pool geometry can be obtained by studying single-line scanning and analyzing the melt pool geometry, using a similar approach as described in the present paper varying $P$ and $v$ in particular. The scanning strategy describes the laser scanning sequence and is normally decided by the operator. Several approaches have been studied and have shown to significantly influence the residual stress and grain structure of as-built part: linear, circular, in-out, out-in, stripes, island, etc. Example of studies of the effect of the scanning strategy can be found in the literature ${ }^{24,43-45)}$. These studies show that the scanning strategy particularly influences the heat history of the built part. The laser power $P$ directly affects the quantity of heat energy locally received by the powder bed for melting. The power must therefore be adjusted to provide sufficient heat for melting together with avoiding an excess of heat which could lead to partial volatilization of certain elements or sputtering of the powder. This obviously depends of the thermal characteristics of the material being processed. Finally, the scanning speed strongly effects the solidification as the faster the scanning speed the faster the solidification speed. More generally, the scanning speed determines the time at which the power source stays in the vicinity of a given point of the powder layer of the consolidated part. This in turn influences again the heat history of the as-built parts with direct impact on their performances.

According to the RSM, the process parameters are given different values and varied independently. Several models have been developed for experimental designs which have been described in detail in the literature ${ }^{40,41)}$. Central composite designs in particular are particularly effective for SLM process parameters optimization. This allows studying five levels, or values, for each parameter. As implied in its name, the RSM requires recoding one or several response(s). These experimental data are fitted using mathematical and statistical technics and typically represented using $2 \mathrm{D}$ or $3 \mathrm{D}$-contour maps therefore illustrating optimal processing windows. For SLM optimization, several responses can be considered: density and/or porosity; microstructure; macroscopic defects such as cracks, distortion and roughness; residual stress; etc. In practice, optimization of the SLM process for a given alloy on a given machine should be carried out in different steps. First trials consist in a rough optimization for avoiding macroscopic defects such as cracks, distortion and excessive roughness. This basically ensures that the as-built parts geometry is consistent with the design with no visible defects. In a second step, the process parameters should be optimized to minimize porosity. This is a great asset of the SLM process to be able to produce fully dense parts with virtually no residual porosity. Optimization of the process parameters towards low residual porosity, typically lower than $1 \%$ although very low porosity below $0.1 \%$ is often possible, is a necessary condition for production of high quality parts and products by SLM. Finally, finer optimization can and should be carried out with consideration of microstructure and residual stress to improve the mechanical properties of as-built parts. The above description highlights the complexity of the SLM process, for which numerous parameters need to be optimized within a narrow processing window allowing production of high quality parts.

\subsection{Materials}

To illustrate the optimization method described in the previous section 2.2, a CoCr-Mo alloy ( $\mathrm{CoCr}$ ) was used in the present study. This allowed to clearly illustrate the efficacy of the method. CoCr-Mo alloys are extensively used in the medical and dental fields due to high strength and stiffness together with good wear and environmental resistance. Applications in aerospace are also common for these alloys. The use of AM and SLM in particular is decidedly sound as it allows high level of complexity and customization. Pre-alloyed powders specifically designed for AM were used, supplied by Sandvik Osprey Ltd. The pre-alloyed powders characteristics are given in Table 1 according to the supplier. The powders were typically mostly spherical, with a Gaussian particle distribution between 10 and $45 \mu \mathrm{m}$, produced by the gas atomization process (Nitrogen 
Table 1 CoCr-Mo powders characteristics

\begin{tabular}{|c|c|c|c|c|}
\hline \multirow{10}{*}{$\begin{array}{l}\text { Chemical } \\
\text { composition } \\
\text { (wt.\%) }\end{array}$} & & \multirow{2}{*}{ Measured } & \multicolumn{2}{|c|}{ ASTM F75 $^{46)}$} \\
\hline & & & Min. & Max. \\
\hline & $\mathrm{Cr}$ & 28.7 & 27 & 30 \\
\hline & Mo & 6.1 & 5 & 7 \\
\hline & $\mathrm{Mn}$ & 0.69 & - & 1 \\
\hline & $\mathrm{Si}$ & 0.68 & - & 1 \\
\hline & $\mathrm{C}$ & 0.25 & - & 0.35 \\
\hline & $\mathrm{Fe}$ & 0.18 & - & 0.75 \\
\hline & $\mathrm{Ni}$ & 0.01 & - & 0.5 \\
\hline & $\mathrm{Co}$ & Bal. & - & Bal. \\
\hline \multirow{3}{*}{$\begin{array}{c}\text { Particle size } \\
(\mu \mathrm{m})\end{array}$} & $\mathrm{d} \leq 10$ & \multicolumn{3}{|c|}{$3.6 \%$} \\
\hline & $10 \leq \mathrm{d} \leq 45$ & \multicolumn{3}{|c|}{$96.3 \%$} \\
\hline & $\geq 45$ & \multicolumn{3}{|c|}{$3.6 \%$} \\
\hline $\begin{array}{l}\text { Tap density } \\
\left(\text { g. } \mathrm{cm}^{-3}\right)\end{array}$ & \multicolumn{4}{|c|}{5.1} \\
\hline
\end{tabular}

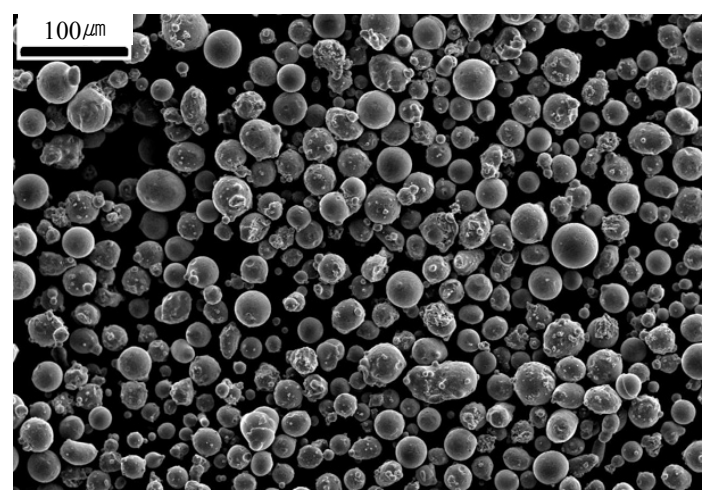

Fig. 1 SEM micrograph of the CoCr-Mo powder used in the present study. Most particles were spherical with a size distribution between 10 and $45 \mu \mathrm{m}$

gas). The morphology of the powders was observed by scanning electron microscopy (SEM) as displayed in Fig. 1 and the composition was approximately confirmed by energy dispersive spectroscopy (EDS).

\subsection{Case study: optimization for the studied alloys}

The scope of the present paper is to describe the methodology for optimization and the value of this approach for successful production of high quality parts. For this reason, the case study was kept relatively simple and constitutes more of a guide line for optimization rather than a definite optimization campaign. Any optimization approach should begin with a thorough literature review. The popularization of the SLM processing of relevant materials over the past decade provides the scientific community with a plethora of published research on the production of alloys, conventional or not. Nevertheless, as mentioned earlier, the influence of a specific equipment and specific powders is non negligible, so that an optimization campaign such as that described in the present article is strongly advised. Here, the strategy was to minimize residual porosity, the so-called response of the RSM. Not only the porosity was measured as described later in section 2.5, the microstructure and hardness of the produced specimens were also analyzed. The method was based on a simplified version of the RSM: the hatch spacing $(h=70 \mu \mathrm{m})$ and the layer thickness $(t=20 \mu \mathrm{m})$ were appropriately studied previously and kept constant, while the laser power (100, $110,130$ and $140 \mathrm{~W})$ and scanning speed $(7 \mathrm{xx}, 8 \mathrm{xx}$, $8 \mathrm{xx}, 9 \mathrm{xx} \mathrm{mm} . \mathrm{s}^{-1}$ ) were varied. The actual scanning speeds are not detailed for proprietary con- siderations. The scanning strategy chosen was an island scanning with an island size of $5.4 \mathrm{~mm}$ and a rotation angle of $67^{\circ}$ between layers. A matrix of sixteen $1 \mathrm{~cm}^{3}$ cubes was therefore produced on a single building plate. The schematic design of the experimental procedure is given in Fig. 2. In Fig. 2, the calculated values of energy density $E_{d}$ according to equation 1 were included in red.

After the production of the sample by SLM according to the matrix design in Fig. 2, the samples were re-

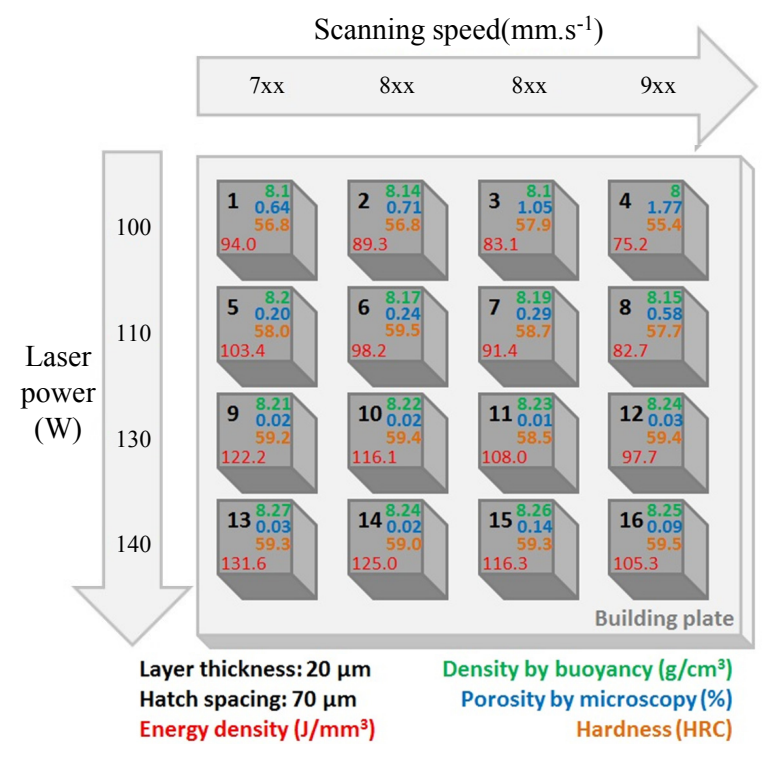

Fig. 2 Schematic of the experimental design used for process parameters optimization for the production of the CoCr-Mo alloy by SLM. The layer thickness and the hatch spacing were kept constant. The scanning speed and the laser power have been varied. The corresponding values of energy density $E_{d}$ according to Eq. (1) are given in red. The values of density $\rho_{s}$ measured by buoyancy method according to Eq. (2) are given in green. The values of porosity $\mathrm{P}_{\%}$ measured by microscopy according to Eq. (3) are given in blue. The values of Brinell hardness are given in orange 
moved from the building platform by means of wire cutting for analysis. The response chosen for optimization as per the RSM was the residual porosity. As previously mentioned, porosity is critical for AM parts and should be as low as possible. Note here that minimizing porosity or maximizing density is equivalent. There are several methods for measuring porosity ${ }^{47)}$ : buoyancy method (Archimedes' principle), optical microscopy (micrograph of cross sections) and X-rays (CT scan). X-ray scanning is a non-destructive technic which allows not only quantifying porosity but also to visually observe porosity all over specimens. It is however not readily available as it requires costly equipment, it is a time-consuming measure and often suffers from definition not allowing detection of very fine pores smaller than $10 \mu \mathrm{m}$. On the other hand, both buoyancy and microscopic methods are fairly easy.

The buoyancy method, also referred to as Archimedes' principle, consists in calculating the density of a sample by measuring the mass of the sample in air and immerged in a liquid of known density using a high precision balance. The density of the sample $\rho_{s}$ (in g. $\mathrm{cm}^{-3}$ ) can easily be calculated according to the following equation:

$$
\rho_{s}=\frac{m_{a}}{m_{a}-m_{l}} \times \rho_{l}
$$

Where $m_{a}$ is the mass of the sample in air $(\mathrm{g}), m_{i}$ is the mass of the sample into the liquid $(\mathrm{g})$ and $\rho_{i}$ is the density of the liquid $\left(\mathrm{g} . \mathrm{cm}^{-3}\right)$. For more simplicity, the liquid is often water and its density is taken as $\rho_{i}=1$ g. $\mathrm{cm}^{-3}$ regardless of temperature. Also note that in Eq. (2), the buoyancy of the sample in air is not taken into account as the density of air is assumed $\rho_{\text {air }}=0 \mathrm{~g} \cdot \mathrm{cm}^{-3}$. For more precision, acetone could be used instead of water, the ambient and the temperature of the liquid can be carefully monitored (as density depends on temperature). However, the approximations described above are usually satisfactory for most investigation. This buoyancy method is non-destructive, can be applied to any sample or part geometry and does not require any specific equipment other than a precision balance and an appropriate density kit. Another significant advantage of this method is that it considers the porosity of the entire part as opposed to the microscopic method described next. An inconvenient limitation however is that it does not give any information of the porosity itself in the sense that it gives no information about the morphology, size and location of pores. These are however important information to understand the nature of porosity: powder or process porosity, inconsistent layer interfaces, inconsistent island boundaries, inappropriate hatch spacing, etc. Another limitation is that it is usually difficult to correlate the measured density to actual residual porosity. The only way to do so would be to compare the actual measured values of density to the theoretical density of the sample. However, in a complex alloy system with several alloying elements and phases, a precise evaluation of the theoretical density is not readily available.

The microscopic method consists in sectioning the samples which, after conventional metallographic preparation, allows direct observation of the porosity by optical microscopy. The section of the samples are conveniently mounted, ground and polished to obtain a flat highly reflective surface. The white light of the optical microscope is therefore reflected except at pores which thus clearly appear as dark surfaces. The amount of porosity $P_{\%}$ (in \%) can therefore be easily computed by:

$$
P_{\%}=\frac{\sum A_{\text {pores }}}{A_{\text {sample }}} \times 100
$$

Where $\Sigma A_{\text {pores }}$ is the sum of the area of each individual pore and $A_{\text {smmple }}$ is the total area of the sample's cross section. This method has several advantages: it is again rather simple and does not require specific equipment other than standard metallurgist equipment, and more importantly it allows direct observation of porosity. Accordingly, porosity can easily be quantified in terms of volume fraction but also the aspect ratio, size and position of pores. This is often necessary to assess the cause of porosity for given process conditions, as it will be discussed later in section 3.2. An obvious limitation of the microscopic method is the local aspect of the measure: it only allows quantifying the porosity in the area of the sample's section observed. This could be misleading at times and a statistical analysis over several sections would be more appropriate at the expense of labor time. This is why it is recommended to combine both buoyancy and microscopic methods. This is the approach described in the present paper. Schematics of both the buoyancy and microscopic methods are given in Fig. 3 for more clarity ${ }^{47)}$.

\subsection{Experimental and analyses procedure}

$1 \mathrm{~cm}^{3}$ specimens were produced by SLM (METALSYS 150) by Winforsys Information Technology Co., Ltd. as described in section 2.4 and separated from the base plate by wire cut electrical discharge machining. The samples were then shipped to the MS\&E department of Changwon National University for complete analysis. The density of each sample was first calculated accord- 


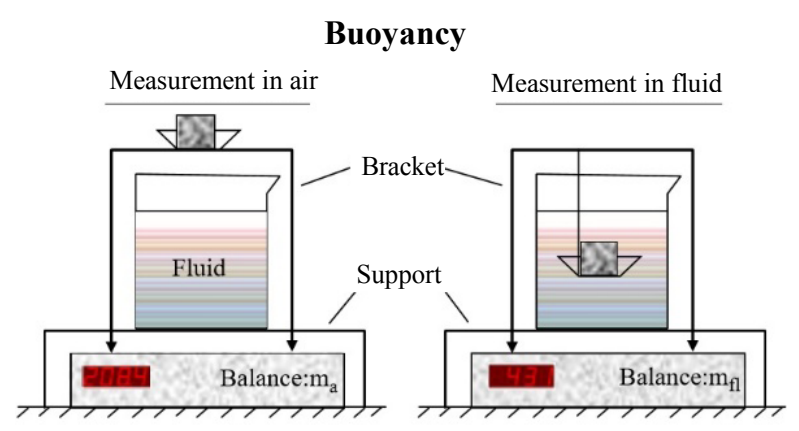

(a)

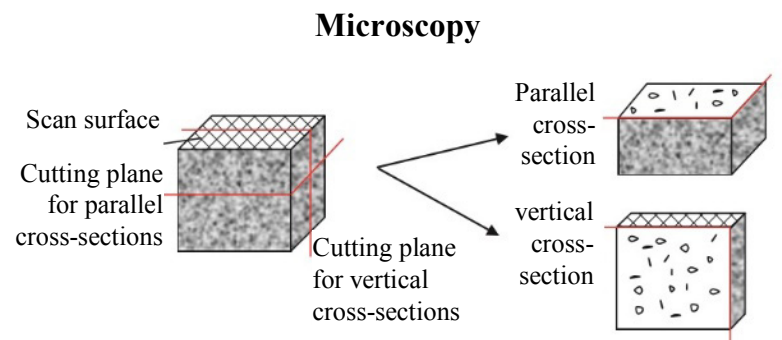

(b)

Fig. 3 Schematics of the (a) buoyancy and (b) microscopy methods for measuring density/porosity ${ }^{47}$ )

ing to the buoyancy method. Samples were roughly ground on each side to remove external roughness. The mass in air and in distilled water was then measured at ambient temperature using a high precision balance (SciLab WBA-320) and a density kit. The density kit consisted in a beaker filled with approximately $250 \mathrm{~mL}$ distilled water, a density pan, a density pan holder and a beaker stand. The density pan, density pan holder and beaker stand were conveniently designed and fabricated in polymer by DLP processing (photopolymerizationbased AM). The measure was repeated at least five times for statistical purpose and the average value of the samples density was calculated according to Eq. (2).

The samples were then sectioned in half in cross section (along the building direction) and hot mounted in a phenolic conductive resin with carbon filler (Struers PolyFast) using an auto mounting press (MTDI MM-100). The mounted specimens were subsequently ground using abrasive SiC papers from grit 400 to 2000 and polished using appropriate cloths and diamond pastes from $9 \mu \mathrm{m}$ down to $1 \mu \mathrm{m}$. They were then thoroughly washed in ethanol using an ultrasonic cleaner (DAIHAN WUC-A10H) for $20 \mathrm{~min}$ at ambient temperature. This allowed to obtain a smooth highly reflective surface. Several optical micrographs were taken at x50 magnification (Nikon EPIPHOT 200) covering the entire sample and were subsequently stitched together into one single image of high quality showing the entire cross section. Such a micrograph shows the dense material in white (reflecting the OM white light) and the pores in black. Using an image analysis software (Image-Pro Plus 6.0), it was therefore easy to quantify porosity in terms of volume fraction by calculating the ratio of pores area over the entire section area according to Eq. (3).

To reveal the microstructure, the samples were electrolytically etched with a solution of (1 dist. water : $1 \mathrm{HNO}_{4}$ ), a voltage of 12-14 $\mathrm{V}$ and a current of approximately 20 A. The surface of the samples was tipped for about $5 \mathrm{~s}$ in three to five positions. Optical micrographs were taken various magnification. The microstructure and composition was also evaluated by SEM-EDS (JEOL JSM5800 operating at $20 \mathrm{keV}$ ) for selected specimens.

Finally, hardness was measured using a digital Rockwell hardness tester (Samil Precision Co. SR-300) with a $150 \mathrm{~kg}$ load. Hardness was measured in five points of a sample (four corners and at the center of the cross section) and the average values of hardness were used.

\section{Results and discussion}

\subsection{Density analysis}

After production by SLM of CoCr-Mo specimens according to the schematic in Fig. 2, the density of each specimen was calculated by buoyancy method according to Eq. (2). Fig. 4(a) shows the average values of the calculated density as a function of the energy density (Eq. (1)) corresponding to the process parameters' sets. In Fig. 4(b) however, the calculated density was plot as a $3 \mathrm{D}$ color map as a function of the scanning speed and the laser power. Fig. 4(a) clearly shows there is a trend as to the relationship between density (or porosity) and energy density of the process: generally speaking, increasing the energy density increases the density or reduces the porosity of the parts. This is intuitive as the higher the energy density the more consistent the melting and therefore the consolidation. However, although it is not highlighted in the present case, it is often referred to a processing window as there is an upper bond for the energy density. A too high energy density may cause significant defects such as turbulent melt pool, evaporation of light elements, boiling, sputtering, high residual stress, microcracking, etc. Although the results exhibited in Fig. 4(a) are valuable, the effect of individual parameters is not evidenced. This is noted by several conditions exhibiting similar values of energy density though the parts densities are significantly different. This indicates that although a minimum energy density of about $100 \mathrm{~J} . \mathrm{mm}^{-3}$ seems appropriate from Fig. 4(a) for maximizing density, any combination according to Eq.(1) may not be satisfactory. This is highlighted in 


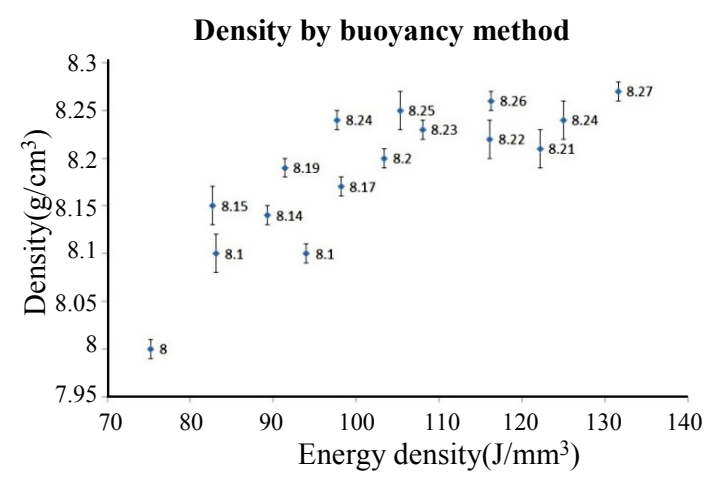

(a)

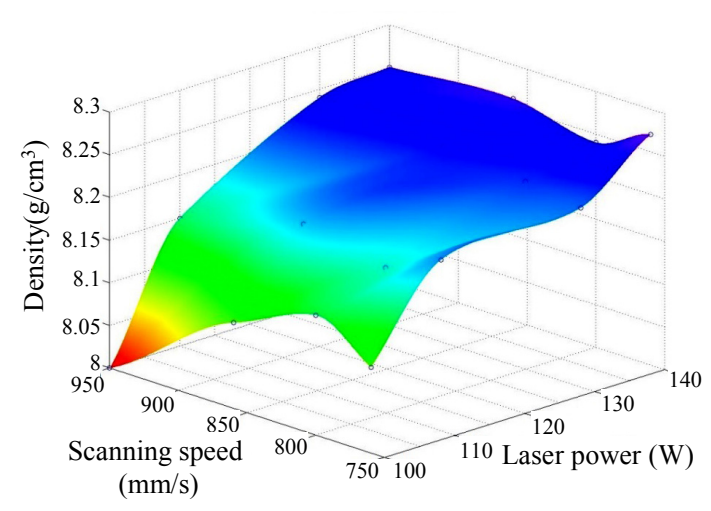

(b)

Fig. 4 Density measured by buoyancy method and calculated according to Eq. (2) for all CoCr-Mo specimens. (a) is the density as a function of the energy density (Eq.(1)) and (b) is the density as function of the scanning speed and laser power

Fig. 4(b) where the individual effect of the scanning speed and the laser power can be assessed. It is shown that the effect of the laser power is clearly more important, although at low power the effect of the scanning speed is significant. The plot in Fig. 4(b) suggests that the laser power should be higher than $120 \mathrm{~W}$.

As mentioned previously, the analysis of the density as a function of the processing conditions is clearly valuable as it is a simple non-destructive method which allows obtaining information regarding the entire parts volume. However, it doesn't give valuable information about the nature of porosity itself. In other words, while it is clear that density and porosity are inversely proportional, the nature of porosity is unknown. Besides, it is difficult to accurately quantify porosity based on density measurements as it is difficult to know with precision the theoretical density of the alloy under study which is very sensitive to the chemical composition and microstructure.

\subsection{Porosity analysis}

The porosity of the as-built parts was measured by mi- croscopy analysis as described in section 2.5. Fig. 5 shows the porosity of all $16 \mathrm{CoCr}-\mathrm{Mo}$ samples along with the actual value of porosity in percent measured on the specific cross section. Similarly to density analysis, Fig. 6(a) shows the average values of the calculated density as a function of the energy density while Fig. 6(b) shows porosity plot as a function of the scanning speed and the laser power.

The results of the porosity analysis by microscopy are consistent with the density analysis in the previous section 3.1: the porosity is basically inversely proportional to the energy density (Fig. 6(a)). The significant role of the laser power over the scanning speed is once again highlighted by Fig. 6(b). The obvious limitation of the results in Fig. 6, inherent to the microscopy method, is that the porosity is measured only on the considered cross section. The risk for statistical error is rather high, which motivates the combination of both the density and microscopy methods. An incremental grinding and polishing procedure could be used to lessen this, however to the expense of consequent time and labor. Besides, the average size of porosity is usually smaller than any conceivable incrementing. The great advantage and complementary outcome however is the ability to actually observe porosity (Fig. 5). There are several identified kinds of porosity ${ }^{15,24,27,32,33,43)}$.

First, "powder porosity" is often found and identified as small spherical pores randomly located. These are found in the starting powder and usually are caused by gas trapped during the gas atomization process for powder production. Although some of these pores will be released during the selective melting, little can be done in this regard from the processing stand point. Nevertheless,

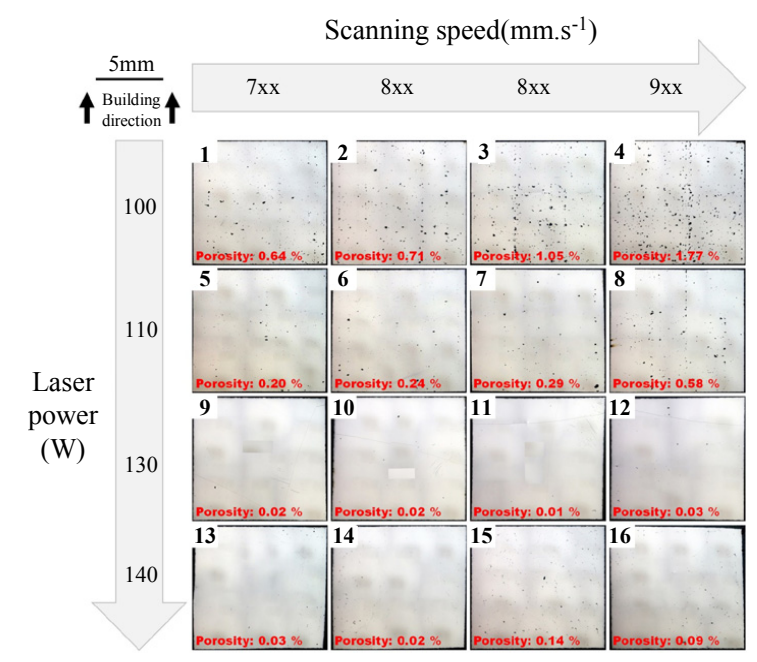

Fig. 5 Optical micrographs showing the porosity of all specimens produced by SLM according to the experimental design. The value of porosity in percent is included for each specimen in red 


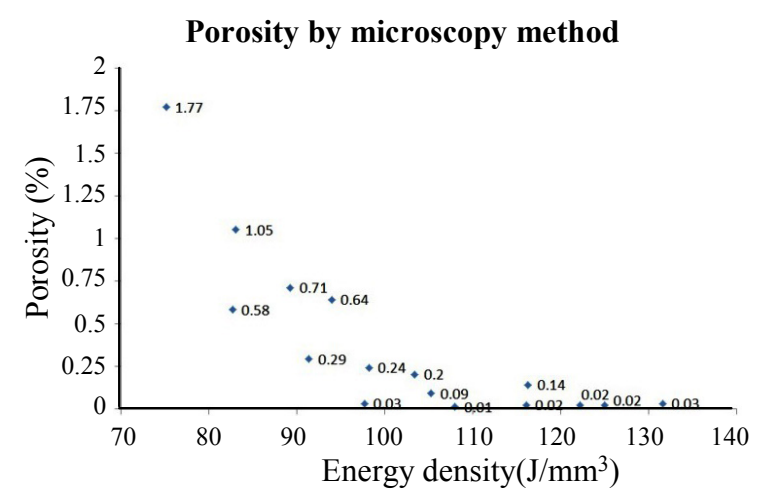

(a)

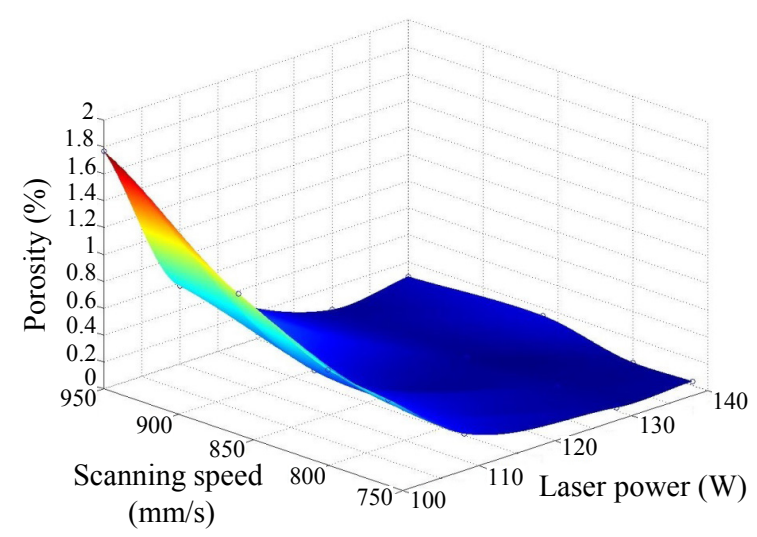

(b)

Fig. 6 Porosity measured by microscopic method and calculated as the ratio of pores area over the sample's cross section area for all CoCr-Mo specimens. (a) is the porosity as a function of the energy density (Eq.(1)) and (b) is the porosity as function of the scanning speed and laser power

this powder porosity is small in volume (obviously smaller than the larger particle size) and spherical therefore not leading to notch effects. For these reasons, they are not significantly detrimental to the properties of the material.

The second kind of frequent porosity can be observed somewhat elongated and aligned along the layer deposition direction, often at layer interfaces. This porosity usually arises from inconsistent consolidation between adjacent layers. Several reasons can be responsible such as inappropriate combination of layer thickness and laser power, inappropriate energy density value, inappropriate powder characteristics in particular packing density or flowability, inappropriate racking mechanism. A clear example of such porosity is given in Fig. 7 for an Alloy 718 produced by SLM. This $1 \mathrm{~cm}^{3}$ specimen shows a porosity of $1.68 \%$ (measured density of $8.06 \mathrm{~g} . \mathrm{cm}^{-3}$ ) for a calculated energy density of $82.3 \mathrm{~J} . \mathrm{mm}^{-3}$. Very large pores are clearly observed along the layer deposition direction. This type of porosity can be referred to

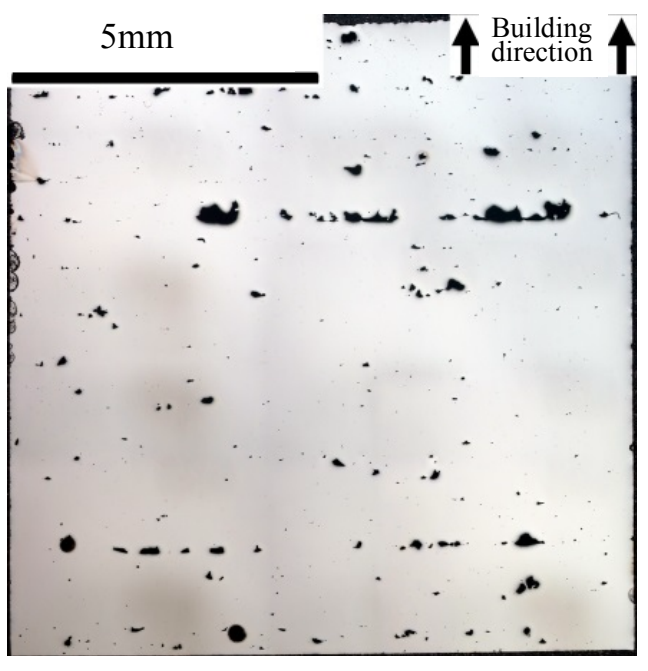

Fig. 7 Optical micrograph of an Alloy 718 produced by $\operatorname{SLM}\left(P=200 \mathrm{~W}, v=900 \mathrm{~mm} \cdot \mathrm{s}^{-}, t=30 \mu \mathrm{m}\right.$ and $\left.h=90 \mu \mathrm{m} ; E_{d}=82.3 \mathrm{~J} . \mathrm{mm}^{-3}\right)$ exhibiting a rather high porosity of $1.68 \%$. Large pores elongated and aligned along the layer deposition direction can clearly be observed, corresponding to "layer porosity"

as "layer porosity".

The third kind of commonly observed porosity is referred to as "hatch porosity". It can be identified as irregular pores aligned along the building direction. This type of porosity is clearly observed in low power specimens in Fig. 5 (samples 1 to 8 corresponding to laser of $100 \mathrm{~W}$ and $110 \mathrm{~W})$. As in the present case, such porosity can be observed at islands or stripes boundary in correspondence to the building strategy. Note in the case of Fig. 5 that in these specific cross sections, the islands corresponding to the building strategy in the present investigation were cut along random planes. It is however evident from the micrographs that a significant cause of porosity in these samples were the islands boundaries. This type of porosity can be referred to as "hatch porosity" as it is caused by inconsistent consolidation between adjacent melting tracks in the layer plane.

There is finally more irregular porosity, referred to as "random porosity". These are more unpredictable and are caused by occasional events such as agglomerated powders, inconsistent protective flow, layer deposition failure, etc.

Although redeemable to some extent as previously suggested, powder porosity is the only source of porosity which can't be dealt with solely by process optimization. The other sources of porosity - baptized layer, hatch and random porosity - are directly related to the SLM process conditions and therefore can virtually be completely eliminated. This is the reason why excellent density, or 
very low residual porosity, can be achieved by SLM and powder bed AM in general. This is highlighted by the present case study where specimens produced with higher laser power (samples 9 to 16 corresponding to laser of $130 \mathrm{~W}$ and $140 \mathrm{~W}$ ) exhibited very low residual porosity well under $0.1 \%$, with mostly traces of only small spherical pores attributed to the powders.

\subsection{Microstructure}

The microstructure of SLM built parts is very specific to this processing method. SLM and more generally powder bed fusion AM processes can be viewed as a micro-welding process, in which selective parts of a powder bed are quickly melted and solidified to join adjacent tracks and superposing layers. The process is usually characterized by fast solidification and cooling rates in the order of $10^{4}$ to $10^{6} \mathrm{~K} / \mathrm{s}^{10,14-16,19,21,23,28,31,36)}$.

This gives rise to a nanodendritic microstructure usually showing high hardness and strength. The very rapid cooling also generates a large number of dislocations in the material which, together with rapid heat cycles, causes high residual stress in the as-built parts. Also due to the nature of the process, the microstructure often exhibit columnar grains along the building direction as a results of remelting of the underlying substrate, according epitaxial solidification and direction of the heat transfer ${ }^{13,15,18,19,21-23,25,27,31,35,43)}$. The process parameters do have a significant influence on the microstructure, and although only optimization through density optimization is presented here, microstructure should also be considered as a critical response. For example, the solidification and cooling rates are strongly affected by the scanning speed. As intuitively understood, the faster the scanning speed the larger the solidification and cooling rates.

Similarly to Fig. 5, the low magnifications of the microstructure of all 16 samples are shown in Fig. 8. The characteristic "fish-scale" aspect of the melt pools is clearly visible. Although not clear in Fig. 8, some typical defects could be identified such as unmelted powder particles and microcracking. The microstructure of sample 11 is given in Fig. 9 for reference. In the optical micrographs in Fig. 9(a) and 9(b), one can note the melt pool depth is larger than $50 \mu \mathrm{m}$ therefore appropriately remelting the underlying substrate (layer thickness $t=$ $20 \mu \mathrm{m})$. Similarly, the melt pool width is approximately $100 \mu \mathrm{m}$ therefore appropriately overlapping adjacent laser tracks (hatch spacing $h=70 \mu \mathrm{m}$ ). Although not clear in Fig. 9(b), the fine dendritic structure with columnar grains intercepting several melt pools is apparent. This is more evident from the SEM micrographs in Figs. 9(c) and $9(\mathrm{~d})$.

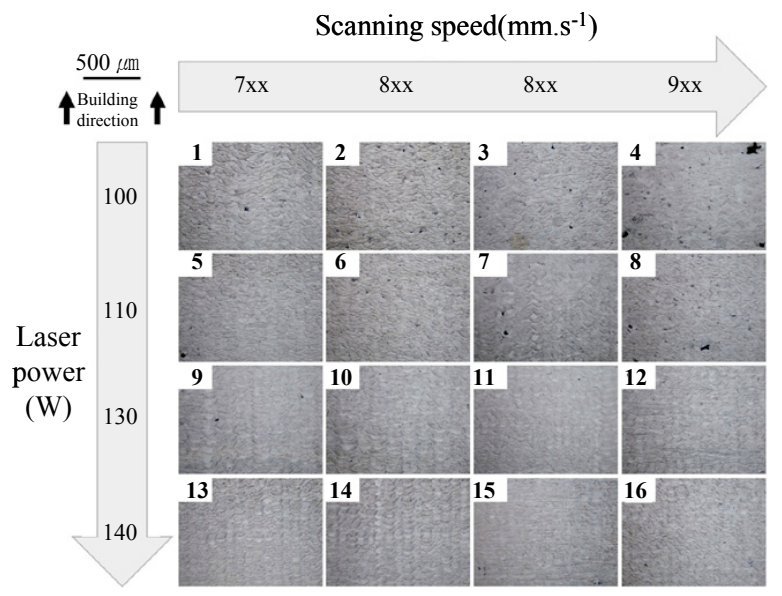

Fig. 8 Low magnification (x100) optical micrographs showing the microstructure of all specimens produced by SLM according to the experimental design
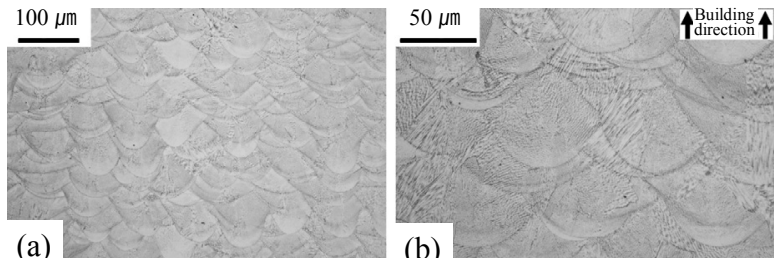

(a)

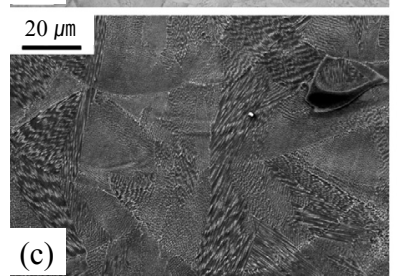

(b)

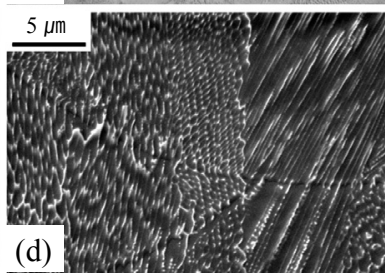

Fig. 9 Microstructure of specimen 11 corresponding to an energy density $E_{d}=82.3 \mathrm{~J} . \mathrm{mm}^{-}{ }^{3}$, a measured density $\rho_{s}=8.23 \mathrm{g.cm}-{ }^{3}$ and a measured porosity of $P_{\%}=0.01 \%$. (a) and (b) are optical micrographs, (c) and (d) are SEM micrographs

\subsection{Hardness}

Fig. 10 shows the Rockwell hardness of all $16 \mathrm{CoCr}-$ Mo samples along with the actual measured average values of hardness. Similarly to density and porosity analyses, Fig. 10(a) shows the average values of hardness as a function of the energy density while Fig. 10(b) shows hardness plot as a function of the scanning speed and the laser power. It should also be noted that the values of hardness measured for all specimens, and particularly those showing the highest density, largely exceed the ASTM F75 requirements of $25 \sim 35 \mathrm{HRC}^{46)}$. This is due as previously mentioned to the very low porosity, the very fine dendritic microstructure and the high density of tangled dislocations. The results of hardness are consistent with those on density and porosity. This in- 


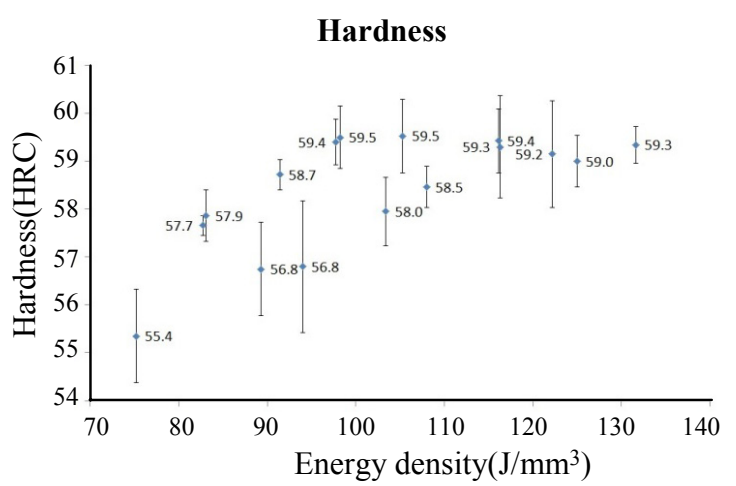

(a)

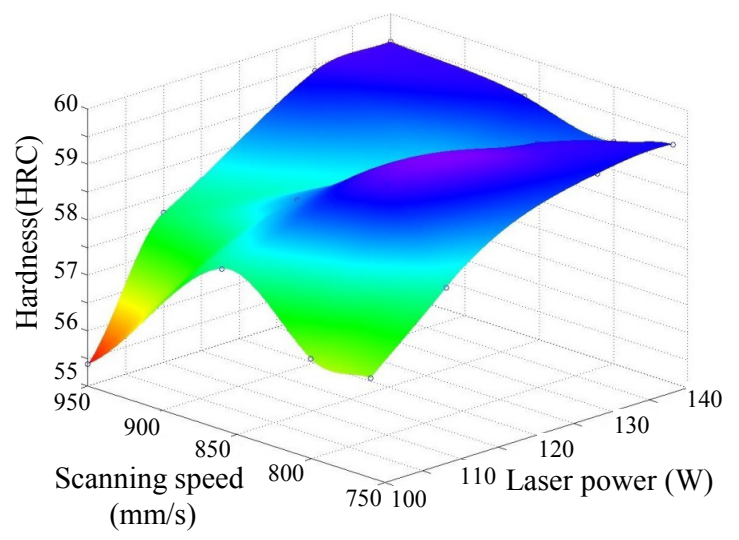

(b)

Fig. 10 Rockwell hardness for all CoCr-Mo specimens measured in five locations and averaged. (a) is the hardness as a function of the energy density (Eq.(1)) and (b) is the hardness as function of the scanning speed and laser power

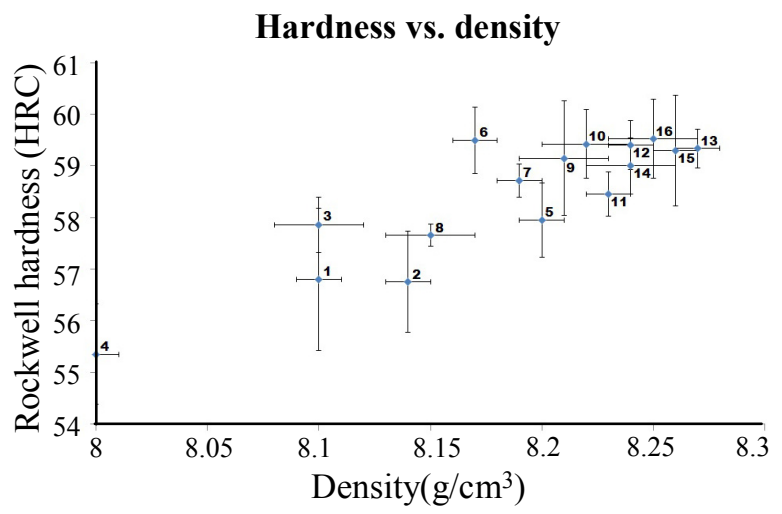

Fig. 11 Rockwell hardness for all $16 \mathrm{CoCr}-\mathrm{Mo}$ specimens plot as a function of the measured density by buoyancy. The label of the specimen according to Fig. 2 was inserted for reference

dicates that although microstructure may slightly differ from one sample to another as a result of different processing conditions, the role of porosity is decidedly more significant on mechanical properties. This was highlighted in Fig. 11 where the measured hardness was plot as a function of the corresponding density for all 16 samples.

\section{Conclusion}

The present paper describes the general method for process parameters optimization based on the response surface methodology for the production of high quality parts and products by Selective Laser Melting, a popular powder bed Additive Manufacturing process. This optimization method consists in producing various specimens of a specific alloy with a specific equipment by varying the key parameters according to a designed matrix and record one or several response(s) characteristic of the as-built material. As an example to illustrate such optimization campaign, a CoCr-Mo alloy was produced with a Winforsys Information Technology Co., Ltd. METALSYS 150 equipment. The laser scanning speed and power were varied and the porosity and hardness were measured for all 16 combinations. This allowed determining an appropriate processing window and in particular the significant effect of the laser power. With considerations on density, properties, processability and production, a high laser power of $P \geq 120$ $\mathrm{W}$ and high scanning speed of $v=850 \sim 950 \mathrm{~mm} \cdot \mathrm{s}^{-1}$ seemed appropriate (layer thickness $t=20 \mu \mathrm{m}$, hatch spacing $h=70 \mu \mathrm{m}$ and island scanning strategy) corresponding to an energy density $E_{d}=90 \sim 120 \mathrm{~J} . \mathrm{mm}^{-3}$. In these conditions, the CoCr-Mo alloy exhibited a very fine dendritic microstructure with columnar grains along the building direction. The materials were characterized by high density $\geq 8.25 \mathrm{~g} . \mathrm{cm}^{-3}$, absence of process porosity and the hardness $\geq 59$ HRC was significantly higher than the requirements for such alloy. The optimization method described in the present paper is highly valuable and should systematically be implemented for producing high quality products by Selective Laser Melting.

\section{Acknowledgments}

This research was supported by Changwon National University in 2017 2018.

ORCID: Mathieu Terner: http://orcid.org/0000-0003-2715-1573

\section{References}

1. M. Terner, The current State, Outcome and Vision of Additive Manufacturing, Journal of Welding and Joining, 33(6) (2015), 495-499

https://doi.org/10.5781/JWJ.2015.33.6.1

2. S. Mellor, L. Hao, D. Zhang, Additive manufacturing, A framework for implementation, Int. J. Production Economics, 
149 (2014), 194-201

https://doi.org/10.1016/j.ijpe.2013.07.008

3. H. Piili, A. Happonen, T. Vaisto, V. Venkataramanan, J. Partanen, A. Salminen, Cost Estimation of Laser Additive manufacturing of Stainless Steel, Physics Procedia, 78 (2015), 388-396 https://doi.org/10.1016/j.phpro.2015.11.053

4. C. Klahn, B. Leutenecker, M. Meboldt, Design for Additive Manufacturing - Supporting the Substitution of Components in Series Products, Procedia CIRP, 21 (2014), 138-143 https://doi.org/10.1016/j.procir.2014.03.145

5. D. Chen, S. Heyer, S. Ibbotson, K. Salonitis, J.G. Steingrimsson, S. Thiede, Digital direct manufacturing, definition, evolution and sustainability implications, Journal of Cleaner Production, 107 (2015), 615-625 https://doi.org/10.1016/j.jclepro.2015.05.009

6. J. Kietzmann, L. Pitt, P. Berthon, Disruptions, decisions, and destinations, Enter the age of 3-D printing and additive manufacturing, Business Horizons, 58 (2015), 209215

https://doi.org/10.1016/j.bushor.2014.11.005

7. B. Vayre, F. Vignat, F. Villeneuve, Identification of some key parameters for assitive manufacturing, application on Electron Beam Melting, Procedia CIRP, 7 (2013), 264-269

https://doi.org/10.1016/j.procir.2013.05.045

8. B.P. Conner, G.P. Manogharan, A.N. Martof, L.M. Rodomsky, C.M. Rodomsky, D.C. Jordan, J.W. Limperos, Making sense of 3-D printing, Creating a map of additive manufacturing products and services, Additive Manufacturing, 1(4) (2014), 64-76

https://doi.org/10.1016/j.addma.2014.08.005

9. M. Baumeurs, P. Dickens, C. Tuck, R. Hague, The cost of additive manufacturing, machine productivity, economies of scale and technology-push, Technological Forecasting \& Social Change, 102 (2016), 193-201 https://doi.org/10.1016/j.techfore.2015.02.015

10. W. Gao, Y. Zhang, D. Ramanujan, K. Ramani, Y. Chen, C.B. Williams, C.C.L. Wang, Y.C. Shin, S. Zhang, P.D. Zavattieri, The status, challenges, and future of additive manufacturing in engineering, Computer-Aided Design, 69 (2015), 65-89 https://doi.org/10.1016/j.cad.2015.04.001

11. ASTM F2792-12a, Standard Terminology for Additive Manufacturing Technologies, (Withdrawn 2015), ASTM International, West Conshohocken, PA, 2012 https://doi.org/10.1520/F2792-12A

12. E. Herderick, Additive Manufacturing of metals: A Review, Materials Science and Technology, MS\&T'11 (2011) 1413-1425

13. W.E. Frazier, Metal Additive Manufacturing, A Review, Journal of Materials Engineering and Performance, 23(6) (2014), 1917-1928 https://doi.org/10.1007/s11665-014-0958-Z

14. C.Y. Yap, C.K. Chua, Z.L. Dong, Z.H. Liu, D.Q. Zhang,
L.E. Loh, S.L. Sing, Review of selective laser melting, Materials and applications, Applied Physics Review, 2 (2015), 041101 https://doi.org/10.1063/1.4935926

15. X. Gong, T. Anderson, K. Chou, Review on powderbased electron beam additive manufacturing technology, Manufacturing Review, 1-2 (2014), 1-12 https://doi.org/10.1051/mfreview/2014001

16. Z. Wang, K. Guan, M. Gao, X. Li, X. Chen, X. Zeng, The microstructure and mechanical properties of deposited-IN718 by selective laser melting, Journal of Alloys and Compounds, 513 (2012), 518-523 https://doi.org/10.1016/j.jallcom.2011.10.107

17. L.N. Carter, K. Essa, M.M. Attallah, Optimization of selective laser melting for a high temperature Ni-superalloy, Rapid Prototyping Journal, 21(4) (2015), 423-432 https://doi.org/10.1108/RPJ-06-2013-0063

18. Y. Lu, S. Wu, Y. Gan, T. Huang, C. Yang, J. Lin, J. Lin, Study on the microstructure, mechanical property and residual stress of SLM Inconel-718 alloy manufactured by differing island scanning strategy, Optics \& Laser Technology, 75 (2015), 197-206 https://doi.org/10.1016/j.optlastec.2015.07.009

19. G. Marchese, X.G. Colera, F. Calignano, M. Lorusso, S. Biamino, P. Minetola, D. Manfredi, Characterization and Comparison of inconel 625 Processed by Selective Laser Melting and Laser Metal Deposition, Advanced Engineering Materials, (2016), 1-9 https://doi.org/10.1002/adem.201600635

20. M. Xia, D. Gu, G. Yu, D. Dai, H. Chen, Q. Shi, Influence of hatch spacing on heat and mass transfer, thermodynamics and laser processability during additive manufacturing of Inconel 718 alloy, International Journal of Machine tools \& Manufacture, 109 (2016), 147-157 https://doi.org/10.1016/j.ijmachtools.2016.07.010

21. S. Li, Q. Wei, Y. Shi, Z. Zhu, D. Zhang, Microstructure Characteristics of Inconel 625 Superalloy Manufactured by Selective Laser Melting, Journal of Materials Science \& Technology, 31 (2015), 946-952 https://doi.org/10.1016/j.jmst.2014.09.020

22. K.N. Amato, S.M. Gaytan, L.E. Murr, E. Martinez, P.W. Shindo, J. Hernandez, S. Collins, F. Medina, Microstructures and mechanical behavior of Inconel 718 fabricated by selective laser melting, Acta Materialia, 60 (2012), 2229-2239 https://doi.org/ 10.1016/j.actamat.2011.12.032

23. G. Marchese, M. Lorusso, S. Patrizia, E. Bassini, J.W. Lee, F. Cagliano, D. Manfredi, M. Terner, H.U. Hong, D. Ugues, M. Lombardi, S. Biamino, Influence of heat treatments on microstructure evolution and mechanical properties of Inconel 625 processed by laser powder bed fusion, Materials Science \& Engineering A, 729 (2018), 64-75 https://doi.org/10.1016/j.msea.2018.05.044 
24. R. Rashid, S.H. Masood, D. Ruan, S. Palanisamy, R.A. Rahman Rashid, M. Brandt, Effect of scan strategy on density and metallurgical properties of 17-4PH parts printed by Selective Laser Melting (SLM), Journal of Materials Processing Tech., 249 (2017), 502-511 https://doi.org/10.1016/j.jmatprotec.2017.06.023

25. L.E. Murr, E. Martinez, J. Hernandez, S. Collins, K.N. Amato, S.M. Gaytan, P.W. Shindo, Microstructures and Properties of 17-4PH Stainless Steel Fabricated by Selective Laser Melting, Journal of Materials Research and Technology, 1(3) (2012), 167-177

https://doi.org/10.1016/S2238-7854(12)70029-7

26. K. Kempen, L. Thijs, J. Van Humbeeck, J.P. Kruth, Mechanical properties of AlSi10Mg produced by Selective Laser Melting, Physics Procedia, 39 (2012), 439-446 https://doi.org/10.1016/j.phpro.2012.10.059

27. J.H. Martin, B.D. Yahata, J.M. Hundley, J.A. Mayer, T.A. Schaedler, T.M. Pollock, 3D printing of high-s trength aluminium alloys, Nature, 549 (2017), 365-369 https://doi.org/10.1038/nature23894

28. E.O. Olakanmi, R.F. Cochrane, K.W. Dalgarno, A review on selective laser sintering/melting (SLS/SLM) of aluminium alloy powders, Processing, microstructure and properties, Progress in Materials Science, 74 (2015), 401-477 https://doi.org/10.1016/j.pmatsci.2015.03.002

29. M. Leary, M. Mazur, J. Elambasseril, M. McMillan, T. Chirent, Y. Sun, M. Qian, M. Easton, M. Brandt, Selective laser melting (SLM) of AlSi12Mg lattice structures, Materials and Design, 98 (2016), 344-357 https://doi.org/10.1016/j.matdes.2016.02.127

30. X.J. Wang, L.C. Zhang, M.H. Fang, T.B. Sercombe, The effect of atmosphere on the structure and properties of a selective laser melted Al-12Si alloy, Materials Science \& Engineering A, 597 (2014), 370-375 https://doi.org/10.1016/j.msea.2014.01.012

31. X. Zhao, S. Li, M. Zhang, Y. Liu, T.B. Sercombe, S. Wang, Y. Hao, R. Yang, L.E. Murr, Comparison of the microstructures and mechanical properties of Ti-6Al$4 \mathrm{~V}$ fabricated by selective laser melting and electron beam melting, Materials and Design, 95 (2016), 21-31 https://doi.org/10.1016/j.matdes.2015.12.135

32. H. Gong, K. Rafi, H. Gu, T. Starr, B. Stucker, Analysis of defect generation in Ti-6Al-4V parts made using powder bed fusion additive manufacturing processes, Additive Manufacturing, 1-4 (2014), 87-98

https://doi.org/10.1016/j.addma.2014.08.002

33. L. Thijs, F. Verhaeghe, T. Craeghs, J.Van Humbeeck, J.-P. Kruth, A study of the microstructureal evolution during selective laser melting of Ti-6Al-4V, Acta Materialia, 58 (2010), 3303-3312 https://doi.org/10.1016/j.actamat.2010.02.004

34. E. Uhlmann, R. Kersting, T.B. Klein, M.F. Cruz, A.V. Borille, Additive manufacturing of titanium alloy for aircraft components, Procedia CIRP, 35 (2015), 55-60 https://doi.org/10.1016/j.procir.2015.08.061

35. B. Vrancken, L. Thijs, J.-P. Kruth, J.V. Humbeeck, Heat treatment of Ti6Al4V produced by Selective laser Melting, Microstructure and Mechanical properties, Journal of Alloys and Compounds, 541 (2012), 177-185 https://doi.org/10.1016/j.jallcom.2012.07.022

36. A.G. Demir, B. Previtali, Additive manufacturing of cardiovascular $\mathrm{CoCr}$ stents by selective laser melting, Materials and Design, 119 (2017), 338-350 https://doi.org/10.1016/j.matdes.2017.01.091

37. E. Liverani, A. Fortunato, A. Leardini, C. Belvedere, S. Siegler, L. Ceschini, A. Ascari, Fabrication of Co-CrNo endoprosthetic ankle devices by means of Selective Laser Melting (SLM), Materials and Design, 106 (2016), 60-68 https://doi.org/10.1016/j.matdes.2016.05.083

38. D. Wang, S. Wu, F. Fu, S. Mai, Y. Yang, Y. Liu, C. Song, Mechanisms and characteristics of spatter generation in SLM processing and its effect on the properties, Materials and Design, 117 (2017), 121-130 https://doi.org/10.1016/j.matdes.2016.12.060

39. H.R. Kim, S.H. Jang, Y.K. Kim, J.S. Son, B.K. Min, K.H. Kim, T.Y. Kwon, Microstructures and Mechanical Properties of CoCr Dental Alloys Fabricated by Three CAD/CAM-Based Processing Techniques, Materials, 9(596) (2016), 1-14 https://doi.org/10.3390/ma9070596

40. R.H. Myers, D.C. Montgomery, C.M. Anderson-Cook, Response Surface Methodology - Process and Product Optimization Using Designed Experiments, John Wiley \& Sons, Inc. (2009) 680 pages. ISBN: 978-0-470- 17446-3

41. M.A. Bezerra, R.E. Santelli, E.P. Oliveira, L.S. Villar, L.A. Escaleira, Response Surface Methodology (RSM) as a tool for optimization in analytical chemistry, Talanta, 76 (2008), 965-977 https://doi.org/10.1016/j.talanta.2008.05.019

42. M. Terner, T.S. Bayarsaikhan, H.U. Hong, J.H. Lee, Influence of Gas Metal Arc Welding Parameters on the Bead Properties in Automatic Cladding, Journal of Welding and Joining, 35(1) (2017), 16-25 https://doi.org/10.5781/JWJ.2017.35.1.16

43. L.N. Carter, C. Martin, P.J. Withers, M.M. Attallah, The influence of the laser scan strategy on grain structure and cracking behavior in SLM powder-bed fabricated nickel superalloy, Journal of Alloys and Compounds, 615 (2014), 338-347 https://doi.org/10.1016/j.jallcom.2014.06.172

44. B. Cheng, S. Shrestha, K. Chou, Stress and deformation evaluations of scanning strategy effect in selective laser melting, Additive Manufacturing, 12 (2016), 240251 https://doi.org/10.1016/j.addma.2016.05.007

45. L. Parry, I.A. Ashcroft, R.D. Wildman, Understanding the effect of laser scan strategy on residual stress in selective laser melting through thermos-mechanical simulation, Additive Manufacturing, 12 (2016), 1-15 .1016/j.addma.2016.05.014 
46. ASTM F75-12, Standard Specification for Cobalt-28 Chromium-6 Molybdenum Alloy Castings and Casting Alloy for Surgical Implants (UNS R30075), ASTM International, West Conshohocken, PA, 2012 https://doi.org/10.1520/F0075-12
47. A.B. Spierings, M. Schneider, R. Eggenberger, Comparison of density measurement techniques for additive manufactured metallic parts, Rapid Prototyping Journal, 17(5) (2011), 380-386

https://doi.org/10.1108/13552541111156504 